\title{
A Multicriteria Decision Making Approach Based on Fuzzy Theory and Credibility Mechanism for Logistics Center Location Selection
}

\author{
Bowen Wang, ${ }^{1}$ Haitao Xiong, ${ }^{1,2,3}$ and Chengrui Jiang ${ }^{1}$ \\ ${ }^{1}$ School of Computer Science and Information Engineering, Beijing Technology and Business University, Beijing 100048, China \\ ${ }^{2}$ School of Computer Science and Engineering, Beihang University, Beijing 100191, China \\ ${ }^{3}$ Collaborative Innovation Centre for State-Owned Assets Administration, Beijing 100048, China
}

Correspondence should be addressed to Haitao Xiong; xionghtao@gmail.com

Received 29 May 2014; Revised 1 August 2014; Accepted 3 August 2014; Published 19 August 2014

Academic Editor: Predrag S. Stanimirovic

Copyright (C) 2014 Bowen Wang et al. This is an open access article distributed under the Creative Commons Attribution License, which permits unrestricted use, distribution, and reproduction in any medium, provided the original work is properly cited.

As a hot topic in supply chain management, fuzzy method has been widely used in logistics center location selection to improve the reliability and suitability of the logistics center location selection with respect to the impacts of both qualitative and quantitative factors. However, it does not consider the consistency and the historical assessments accuracy of experts in predecisions. So this paper proposes a multicriteria decision making model based on credibility of decision makers by introducing priority of consistency and historical assessments accuracy mechanism into fuzzy multicriteria decision making approach. In this way, only decision makers who pass the credibility check are qualified to perform the further assessment. Finally, a practical example is analyzed to illustrate how to use the model. The result shows that the fuzzy multicriteria decision making model based on credibility mechanism can improve the reliability and suitability of site selection for the logistics center.

\section{Introduction}

In modern society, logistics systems have become essential in ensuring economic development and the normal function of the society and the suitability of site selection for the logistics center have direct impact on the efficiency of logistics systems; therefore, a reasonable approach of site selection must be adopted. When selecting the location for the logistics center, not only quantitative factors like costs and distances but also qualitative factors such as natural conditions and infrastructure conditions should be taken into consideration; unlike traditional approaches' ignorance of qualitative factors, multicriteria decision making approach based on fuzzy theory takes both groups of factors into consideration. Hence, it is of great importance to conduct researches on multicriteria decision making approach based on fuzzy theory.
Fuzzy theory was firstly introduced to measure the impacts of qualitative factors on results in real life, which cannot be measured by traditional algorithms. An analytical network process tool was used to select suitable facility locations by Tuzkaya et al. [1]. The analytic hierarchy process (AHP) is a structured technique which has been widely used for organizing and analyzing complex decisions and can take both qualitative and quantitative factors into consideration. Badri offered a method which combined AHP and goal program modeling approach for international facility location problem [2]. Intelligent algorithm like genetic algorithm was also used in the multicriteria decision making problem. For example, a modified multicriterion optimization genetic algorithm was proposed for order distribution in collaborative supply chain [3]. A combination of genetic algorithm and AHP model was developed to solve distribution network problems in supply chain management [4]. But these methods mentioned above could only deal 
with facility location problem under certain environment. To solve distribution network problems under uncertain environment, new methods were proposed; for instance, an algorithm for facility site selection based on fuzzy theory and hierarchical structure analysis was proposed to deal with facility site selection problem under uncertain environment [5]. Chan et al. introduced a fuzzy-AHP approach in the global supplier selection problem [6]. In order to resolve the ambiguity of concepts that are associated with human being's judgments, a fuzzy TOPSIS model under group decision making to solve the facility location selection problem was built for evaluating facility locations $[7,8]$. Liu et al. have introduced an approach which combined fuzzy theory and rough sets in the distribution center location problem [9]. Kahraman et al. used four fuzzy multiattribute group decision making approaches for alternative locations, with which uncertainty and vagueness from subjective perception can be effectively represented and reached to a more effective decision [10]. Chan and Prakash have proposed a new kind of maintenance policy selection approach using the fuzzy multicriteria decision making approach [11]. Lee and Lin introduced a fuzzy simple additive weighting approach with objective and subjective criteria under group decision making for location selection [12]. In order to calculate criteria values under uncertain environment to evaluate and select the suitable location for building logistic center, a fuzzy TOPSIS model was built by Zadeh [13]. However, the literature listed above neglects the impacts of consistency and historical assessment accuracy of decision makers on the results and thus cannot ensure the accuracy of site selection result.

In response to the problem above, this paper firstly defined the criteria set of the logistics center location selection in Section 2 and then introduced the definitions and notations related to the fuzzy theory and the credibility mechanism, including the linguistic variables, the membership function, the consistency ranking mechanism, the spearman ranking correlation coefficient, and the historical assessment accuracy in Section 3. In Section 4, the multicriteria decision making model based on fuzzy theory and credibility mechanism is established. In the end, a numerical example is analyzed to illustrate how to use the model. The result shows that the approach proposed in this paper can improve the reliability of the result for site selection.

\section{Defining and Selecting Location Criteria}

Since the criteria will be used to evaluate the potential location for the logistics center, it is of great importance to select a justified set of criteria to ensure the rationality of final result [14]. In this paper, factors shown in Table 1 will be used as the criteria set for the logistics center location selection.

(1) Cost. In the process of location selection, factors such as land cost, operation cost, and labor costs should be taken into comprehensive consideration.

(2) Distance to Supplier. It is also called internal traffic convenience, having great effect on the transportation cost.
TABLE 1: Criteria for location selection.

\begin{tabular}{lc}
\hline Criterion & Unit of Measurement \\
\hline Costs $\left(C_{1}\right)[10]$ & Quantitative \\
Distance to Suppliers $\left(C_{2}\right)$ & Quantitative \\
Distance to Customers $\left(C_{3}\right)$ & Quantitative \\
Natural Conditions $\left(C_{4}\right)$ & Qualitative \\
Conformance to other means of & Qualitative \\
transportation $\left(C_{5}\right)$ & Qualitative \\
Infrastructure conditions $\left(C_{6}\right)$ & \\
\hline
\end{tabular}

TABLE 2: Linguistic terms for objective ratings.

\begin{tabular}{lc}
\hline Linguistic Term & Membership function \\
\hline Very poor (VP) & $(1,1,3)$ \\
Poor (P) & $(1,3,5)$ \\
Fair (F) & $(3,5,7)$ \\
Good (G) & $(5,7,9)$ \\
Very good (VG) & $(7,9,9)$ \\
\hline
\end{tabular}

TABLE 3: Linguistic terms for criteria ratings.

\begin{tabular}{lc}
\hline Linguistic term & Membership function \\
\hline Very low (VL) & $(1,1,3)$ \\
Low $(\mathrm{L})$ & $(1,3,5)$ \\
Medium (M) & $(3,5,7)$ \\
High $(\mathrm{H})$ & $(5,7,9)$ \\
Very high $(\mathrm{VH})$ & $(7,9,9)$ \\
\hline
\end{tabular}

(3) Distance to Customer. It is also called external traffic convenience, affecting the distribution efficiency and the transportation cost directly.

(4) Natural Conditions. They mainly include the meteorological conditions, the terrain conditions, and the hydrologic conditions.

(5) Conformance to Other Means of Transportation. In modern logistics systems, intermodal transportation is usually adopted; therefore, good compatibility on different mode of transportation will ensure the efficiency of the transportation of cargos.

(6) Infrastructure Conditions. They mainly include the reliability of the infrastructure and convenience of communication systems.

\section{Definitions and Notations}

3.1. Defining the Linguistic Variables. In this paper, linguistic variables ranging from a scale of 1 to 9 for rating the criteria and the potential locations for the logistics center will be used, as illustrated in Tables 2 and 3.

3.2. Defining the Membership Function. Triangular membership function, trapezoidal membership function, Gaussian membership function, and bell-shaped membership function 


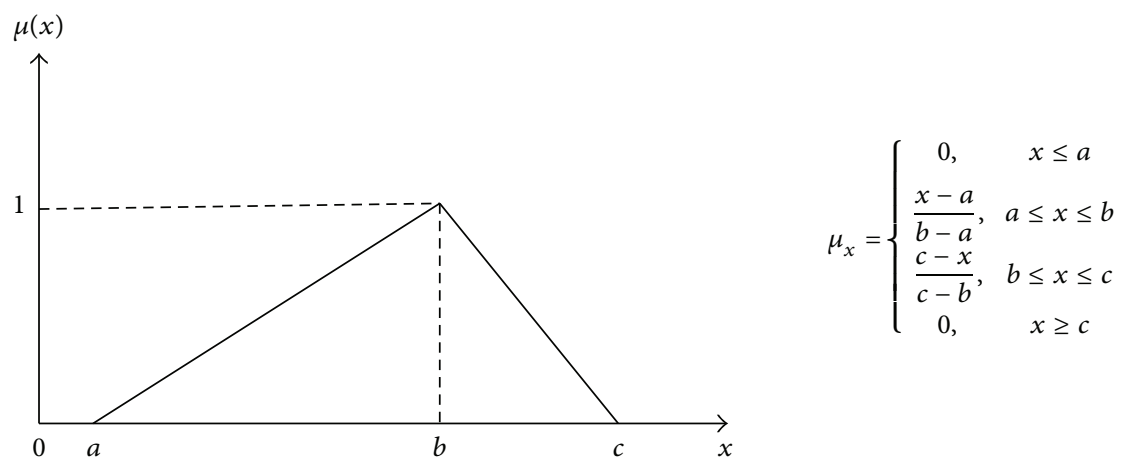

FIgURE 1: Triangular membership function.

are commonly used [15]; in this paper, the triangular membership function will be used and the membership function of triangular fuzzy number $x$ is defined as illustrated in Figure 1.

3.3. Defining the Credibility Mechanism. The credibility mechanism proposed in this paper mainly includes two aspects: the consistency level and the historical assessment accuracy; they are introduced as follows.

3.3.1. Defining the Consistency Ranking Mechanism. $C_{i}$ and $C_{j}$ are two random criterias in the criterion set; $U_{i j}$ is the qualitative value used to describe the significance of criteria $C_{i}$ and $C_{j}$. Stipulation. If an expert finds that $C_{i}$ is more important than $C_{j}$, then $U_{i j}=1, U_{j i}=0$; if $C_{i}$ is as important as $C_{j}$, then $U_{i j}=U_{j i}=0.5$; if $C_{j}$ is more important than $C_{i}$, then $U_{i j}=0, U_{j i}=1$. So, a binary qualitative ranking matrix can be conducted as $U=\left(U_{i j}\right)_{m \times n}, U_{i j}$ can only be $0,0.5$ or 1 , and $S_{i}$ is the sum of elements in row $i$. The value of $U_{i j}$ also satisfies the following equations:

$$
\begin{gathered}
U_{i j}+U_{j i}=1 ; \quad(i \neq j ; i=1,2, \ldots, m ; j=1,2, \ldots, m), \\
U_{i j}=U_{j i}=0.5 ; \quad(i=j ; i=1,2, \ldots, m ; j=1,2, \ldots, m) .
\end{gathered}
$$

Then, according to the ranking of numeric value of $S_{i}$, the consistency ranking of the significance about the criterion set provided by that expert can be decided.

3.3.2. Defining the Spearman Ranking Correlation Coefficient. Spearman ranking correlation coefficient is used to solve problems which are hard to calculate in numbers or to analyze by using simple correlation coefficient $[16,17]$. In this paper, we can use spearman ranking correlation coefficient to conduct consistency check on criterion rankings provided by different experts.

Define the ranking result provided by expert $p$ as $A_{p}=$ $\left(a_{1 p}, a_{2 p}, \ldots, a_{i p}, \ldots, a_{m p}\right)$, in which $a_{i p}$ is the $i$ th element in the ranking result provided by expert $p$.

Define the ranking result provided by expert $q$ as $A_{q}=$ $\left(a_{1 q}, a_{2 q}, \ldots, a_{i q}, \ldots, a_{m q}\right)$, in which $a_{i q}$ is the $i$ th element in the ranking result provided by expert $q$.
Then the ranking correlation coefficient of rankings provided by expert $p$ and expert $q$ : the spearman ranking correlation coefficient is $\rho_{p q}$.

Defining $\overline{\rho_{p}}$ as the mean value of the spearman ranking correlation coefficient, it represents the consistency level of a certain expert.

3.3.3. Defining the Historical Assessment Accuracy. The accuracy of the historical assessment has great effect on the credibility of a certain expert; therefore, in this section, define $N_{t}(p, i)$ as the number of times expert $p$ provided right performance rating for criterion $i$ in the historical assessment; define $N_{f}(p, i)$ as the number of times expert $p$ provided wrong performance rating for criterion $i$ in the historical assessment. $A_{p i}$ is the historical assessment accuracy of expert $p$ with respect to criterion $i$; it is based on the mutual history of expert $p$ and criterion $i . \overline{A_{p}}$ is the mean value of the historical assessment accuracy of expert $p$ with respect to all the criteria; it represents the accuracy level of a certain expert.

3.3.4. Define the Credibility of the Experts. From the analysis above, the credibility of an expert is defined as the comprehensive effect of the consistency level and the accuracy level of an expert. Therefor, the credibility of expert $p$ could be defined as

$$
C_{p}=\alpha \overline{\rho_{p}}+(1-\alpha) \overline{A_{p}} .
$$

The main function of the credibility of the experts is to eliminate the rankings failing to pass the credibility check. The standard of elimination calculates the value of the credibility of a certain expert; experts can continue to participate in the following assessment only when the value exceeds certain threshold value $T$; otherwise the assessment result of the expert will be eliminated.

\section{Fuzzy Multicriteria Decision Making Model Establishing}

Suppose that there is a committee of $n$ experts $\left(k_{1}, k_{2}, \ldots, k_{n}\right)$ who are responsible for assessing the performance of $m$ potential locations $L=\left(L_{1}, L_{2}, \ldots, L_{m}\right)$ in respect to $k$ criteria $C=\left(C_{1}, C_{2}, \ldots, C_{k}\right)$, the weights of the criteria are 
denoted by $W_{i}(i=1,2, \ldots, m)$; the performance ratings of expert $k$ for location $j$ with respect to criterion $i$ are denoted by $X_{i j k}(i=1,2, \ldots, k ; j=1,2, \ldots, m ; k=1,2, \ldots, n)$; $U^{n}=\left(U_{i j}\right)_{m \times n}$ is the binary qualitative ranking matrix of a certain logistic center provided by expert $k_{n}$, and $U_{i j}$ is the qualitative value used to describe the significance of criteria $C_{i}$ and $C_{j}$. The multicriteria decision making model based on fuzzy theory and consistency mechanism can be described by the following steps.

Step 1. Conduct expert selection according to the credibility mechanism.

Step 1.1. Define $S_{i}$ as the sum of elements in row in $U_{i j}$; compute $S_{i}$ :

$$
S_{i}=\sum_{k=1}^{m} U_{i k} ; \quad(i=1,2, \ldots, m)
$$

Step 1.2. Get the consistency ranking for the 6 criteria.

Step 1.3. Compute the spearman ranking correlation coefficient $\rho_{p q}$ :

$$
\rho_{p q}=1-\frac{\left[6 \sum_{i=1}^{m}\left(a_{i p}-a_{i q}\right)^{2}\right]}{m\left(m^{2}-1\right)} .
$$

Step 1.4. Compute the mean value of the spearman ranking correlation coefficient.

In order to take the ranking correlation coefficient of the experts into a comprehensive comparison and select the appropriate experts for further assessment, compute the mean value of the spearman ranking correlation coefficient $\overline{\rho_{p}}$ :

$$
\overline{\rho_{p}}=\frac{\sum_{q=1}^{k} \rho_{p q}}{k}
$$

Step 1.5. Compute the historical assessment accuracy of expert $p$ with respect to criterion $i$ :

$$
A_{p i}=\frac{N_{t}(p, i)}{N_{t}(p, i)+N_{f}(p, i)} ; \quad 0 \leq A_{p i} \leq 1 .
$$

Step 1.6. Compute the mean value of the historical assessment accuracy of the experts:

$$
\overline{A_{p}}=\frac{\sum_{i=1}^{k} A_{p i}}{p}
$$

Step 1.7 (compute the credibility of the experts according to (1)). Experts can continue to participate in the following assessment only when the value of the credibility exceeds certain threshold value $T$; otherwise the assessment result of the expert will be eliminated.

Step 2 (compute the aggregate fuzzy weights of each criteria). The aggregate fuzzy rating for criterion $i$ of all the experts is described as $R_{i}=\left(a_{i}, b_{i}, c_{i}\right)$, with

$$
\begin{gathered}
R_{i}=\left(a_{i}, b_{i}, c_{i}\right) ; \\
a_{i}=\min \left\{a_{i k}\right\} ; \quad b_{i}=\frac{1}{k} \sum_{k=1}^{k}\left\{b_{i k}\right\} ; \quad c_{i}=\max \left\{c_{i k}\right\} .
\end{gathered}
$$

Step 3 (evaluate the aggregate fuzzy rating of potential locations). The aggregate fuzzy rating for potential location $j$ with respect to criterion $i$ of all the experts is described as $R_{i j}=\left(a_{i j}, b_{i j}, c_{i j}\right)$, with

$$
R_{i j}=\left(a_{i j}, b_{i j}, c_{i j}\right)
$$

$$
a_{i j}=\min \left\{a_{i j k}\right\} ; \quad b_{i j}=\frac{1}{k} \sum_{k=1}^{k}\left\{b_{i j k}\right\} ; \quad c_{i j}=\max \left\{c_{i j k}\right\} .
$$

Step 4 (normalize the aggregate fuzzy ratings). In order to bring the various criteria scales into a comparable one, the aggregate fuzzy ratings must be normalized; define $\overline{R_{i j}}$ as the fuzzy rating for $R_{i j}$ after being normalized, with

$$
\overline{R_{i j}}=\left(\frac{a_{i j}}{c_{i j}}, \frac{b_{i j}}{c_{i j}}, \frac{c_{i j}}{c_{i j}}\right), \quad f_{i} \in B,
$$

$B$ : criteria having positive effects on location selection,

$$
\overline{R_{i j}}=\left(\frac{a_{i j}}{c_{i j}}, \frac{a_{i j}}{b_{i j}}, \frac{a_{i j}}{a_{i j}}\right), \quad f_{i} \in C,
$$

$C$ : criteria having negative effects on location selection.

Step 5 (calculate the final fuzzy evaluation for potential locations). Considering the different importance of each criterion, define the final fuzzy evaluation value of each potential location as $p_{i}$, with

$$
p_{i}=\sum_{j=1}^{n} \overline{R_{i j}} \times R_{i}, \quad i=1,2, \ldots, m .
$$

Step 6 (compare the potential locations). $p_{i}$ is triangular fuzzy number, so it is very difficult for experts to determine which location is the best directly. This paper conducts a pairwise comparison of $p_{i}$ and $p_{j}$ to show what is the preferable over two potential locations $L_{i}$ and $L_{j}$.

Step 6.1. Define the difference between $L_{i}$ and $L_{j}$ as

$$
Z_{i j}=p_{i}-p_{j}
$$


Step 6.2 (define the fuzzy preference matrix). $E=\left[e_{i j}\right]$ is the fuzzy preference matrix, $e_{i j}$ represents the degree of preference of location $L_{i}$ over location $L_{j}(i, j=1,2, \ldots, m)$, and the fuzzy preference relation between $L_{i}$ and $L_{j}$ is defined as

$$
\begin{gathered}
e_{i j}=\frac{S_{1}}{S}, \quad S>0, \text { with } S_{1}=\int_{x>0} u_{z_{i j}}(x) d x, \\
s=\int_{x>0} u_{z_{i j}}(x) d x+\int_{x<0} u_{z_{i j}}(x) d x .
\end{gathered}
$$

Step 6.3. Define the preference relation between $L_{i}$ and $L_{j}$ as

$$
\begin{aligned}
& L_{i}>L_{j}, \quad e_{i j}>0.5, \\
& L_{i}=L_{j}, \quad e_{i j}=0.5, \\
& L_{i}<L_{j}, \quad e_{i j}<0.5 .
\end{aligned}
$$

\section{Application}

A new logistics center is needed in a city. There are three potential locations, $L_{1}, L_{2}, L_{3}$, and five experts, $K_{1}, K_{2}, K_{3}, K_{4}, K_{5}$, intended to select the best location in respect to 6 criteria shown in Table 1. The criteria are compared in pairs by the experts, and the binary qualitative ranking matrix provided by the 5 experts is shown as follows:

$$
\begin{aligned}
U^{1} & =\left[\begin{array}{cccccc}
0.5 & 1 & 1 & 1 & 1 & 1 \\
0 & 0.5 & 1 & 1 & 1 & 1 \\
0 & 0 & 0.5 & 1 & 1 & 1 \\
0 & 0 & 0 & 0.5 & 1 & 1 \\
0 & 0 & 0 & 0 & 0.5 & 1 \\
0 & 0 & 0 & 0 & 0 & 0.5
\end{array}\right], \\
U^{2} & =\left[\begin{array}{cccccc}
0.5 & 1 & 1 & 1 & 1 & 1 \\
0 & 0.5 & 1 & 1 & 1 & 1 \\
0 & 0 & 0.5 & 1 & 1 & 1 \\
0 & 0 & 0 & 0.5 & 1 & 0 \\
0 & 0 & 0 & 0 & 0.5 & 0 \\
0 & 0 & 0 & 1 & 1 & 0.5
\end{array}\right], \\
U^{3} & =\left[\begin{array}{cccccc}
0.5 & 1 & 1 & 1 & 1 & 1 \\
0 & 0.5 & 1 & 1 & 1 & 1 \\
0 & 0 & 0.5 & 0 & 1 & 1 \\
0 & 0 & 1 & 0.5 & 1 & 1 \\
0 & 0 & 0 & 0 & 0.5 & 1 \\
0 & 0 & 0 & 0 & 0 & 0.5
\end{array}\right], \\
U^{4} & =\left[\begin{array}{cccccc}
0.5 & 1 & 1 & 1 & 1 & 1 \\
0 & 0.5 & 0 & 1 & 1 & 1 \\
0 & 1 & 0.5 & 1 & 1 & 1 \\
0 & 0 & 0 & 0.5 & 0 & 1 \\
0 & 0 & 0 & 1 & 0.5 & 1 \\
0 & 0 & 0 & 0 & 0 & 0.5
\end{array}\right],
\end{aligned}
$$

$$
U^{5}=\left[\begin{array}{cccccc}
0.5 & 1 & 0 & 1 & 1 & 1 \\
0 & 0.5 & 0 & 1 & 1 & 1 \\
1 & 1 & 0.5 & 1 & 1 & 1 \\
0 & 0 & 0 & 0.5 & 1 & 0 \\
0 & 0 & 0 & 0 & 0.5 & 0 \\
0 & 0 & 0 & 1 & 1 & 0.5
\end{array}\right]
$$

The steps to be taken are described as follows.

Step 1. Conduct expert selection according to the credibility mechanism.

Step 1.1. Compute the sum of the elements of rows in $U^{1}$ using (3):

$$
\begin{array}{lll}
S_{1}^{1}=5.5 ; & S_{2}^{1}=3.5 ; & S_{3}^{1}=3.5 ; \\
S_{4}^{1}=2.5 ; & S_{5}^{1}=1.5 ; & S_{6}^{1}=0.5 .
\end{array}
$$

Step 1.2. Get the consistency ranking for the 6 criteria.

The consistency ranking for the 6 criteria provided by expert $k_{1}$ is $C_{1}>C_{2}>C_{3}>C_{4}>C_{5}>C_{6}$.

The consistency ranking for the 6 criteria provided by expert $k_{2}$ is $C_{1}>C_{2}>C_{3}>C_{6}>C_{4}>C_{5}$.

The consistency ranking for the 6 criteria provided by expert $k_{3}$ is $C_{1}>C_{2}>C_{4}>C_{3}>C_{5}>C_{6}$.

The consistency ranking for the 6 criteria provided by expert $k_{4}$ is $C_{1}>C_{3}>C_{2}>C_{5}>C_{4}>C_{6}$.

The consistency ranking for the 6 criteria provided by expert $k_{5}$ is $C_{3}>C_{1}>C_{2}>C_{6}>C_{4}>C_{5}$.

Step 1.3. Compute the spearman ranking correlation coefficient using (4).

The spearman ranking correlation coefficient between $k_{1}$ and $k_{2}$ is $\rho_{12}=0.83$.

The spearman ranking correlation coefficient between $k_{1}$ and $k_{3}$ is $\rho_{13}=0.94$.

The spearman ranking correlation coefficient between $k_{1}$ and $k_{4}$ is $\rho_{14}=0.89$.

The spearman ranking correlation coefficient between $k_{1}$ and $k_{5}$ is $\rho_{15}=0.66$.

Step 1.4. Compute the mean value of the spearman ranking correlation coefficient using (5).

The mean value of the spearman ranking correlation coefficient between expert $k_{1}$ and all the other experts is

$$
\begin{aligned}
\overline{\rho_{1}} & =\frac{\rho_{12}+\rho_{13}+\rho_{14}+\rho_{15}}{4} \\
& =\frac{0.83+0.94+0.89+0.66}{4}=0.83 .
\end{aligned}
$$


TABLE 4: Mutual history of the experts with respect to each criterion.

\begin{tabular}{|c|c|c|c|c|c|c|c|c|c|c|}
\hline \multirow{3}{*}{ Criterion } & \multicolumn{10}{|c|}{ Experts } \\
\hline & \multicolumn{2}{|c|}{$k_{1}$} & \multicolumn{2}{|c|}{$k_{2}$} & \multicolumn{2}{|c|}{$k_{3}$} & \multicolumn{2}{|c|}{$k_{4}$} & \multicolumn{2}{|c|}{$k_{5}$} \\
\hline & $N_{t}(p, i)$ & $N_{f}(p, i)$ & $N_{t}(p, i)$ & $N_{f}(p, i)$ & $N_{t}(p, i)$ & $N_{f}(p, i)$ & $N_{t}(p, i)$ & $N_{f}(p, i)$ & $N_{t}(p, i)$ & $N_{f}(p, i)$ \\
\hline$C_{1}$ & 3 & 3 & 4 & 3 & 2 & 2 & 5 & 0 & 4 & 4 \\
\hline $\mathrm{C}_{2}$ & 4 & 1 & 3 & 0 & 4 & 5 & 2 & 3 & 2 & 3 \\
\hline$C_{3}$ & 3 & 2 & 6 & 0 & 3 & 1 & 4 & 0 & 2 & 1 \\
\hline$C_{4}$ & 4 & 0 & 2 & 2 & 2 & 6 & 6 & 3 & 5 & 0 \\
\hline$C_{5}$ & 4 & 1 & 3 & 2 & 3 & 3 & 9 & 0 & 8 & 4 \\
\hline$C_{6}$ & 2 & 2 & 6 & 0 & 3 & 3 & 8 & 0 & 9 & 8 \\
\hline
\end{tabular}

TABLE 5: Credibility of experts with respect to each criterion.

\begin{tabular}{lccccc}
\hline Criterion & \multicolumn{5}{c}{ Experts } \\
& $k_{1}$ & $k_{2}$ & $k_{3}$ & $k_{4}$ & $k_{5}$ \\
\hline$C_{1}$ & 0.5 & 0.57 & 0.5 & 1 & 0.5 \\
$C_{2}$ & 0.8 & 1 & 0.44 & 0.4 & 0.4 \\
$C_{3}$ & 0.6 & 1 & 0.75 & 1 & 0.67 \\
$C_{4}$ & 1 & 0.5 & 0.25 & 0.67 & 1 \\
$C_{5}$ & 0.8 & 0.6 & 0.5 & 1 & 0.67 \\
$C_{6}$ & 0.5 & 1 & 0.5 & 1 & 0.53 \\
\hline
\end{tabular}

TABLE 6: The performance rating of the 6 criteria.

\begin{tabular}{lccc}
\hline Criterion & \multicolumn{3}{c}{ Experts assessments } \\
& $k_{1}$ & $k_{2}$ & $k_{4}$ \\
\hline$C_{1}$ & $\mathrm{VH}$ & $\mathrm{VH}$ & $\mathrm{VH}$ \\
$C_{2}$ & $\mathrm{M}$ & $\mathrm{L}$ & $\mathrm{M}$ \\
$C_{3}$ & $\mathrm{H}$ & $\mathrm{VH}$ & $\mathrm{VH}$ \\
$C_{4}$ & $\mathrm{VH}$ & $\mathrm{H}$ & $\mathrm{VH}$ \\
$C_{5}$ & $\mathrm{H}$ & $\mathrm{M}$ & $\mathrm{H}$ \\
$C_{6}$ & $\mathrm{VH}$ & $\mathrm{VH}$ & $\mathrm{H}$ \\
\hline
\end{tabular}

The mean value of the spearman ranking correlation coefficient between expert $k_{2}$ and all the other experts is

$$
\begin{aligned}
\overline{\rho_{2}} & =\frac{\rho_{21}+\rho_{23}+\rho_{24}+\rho_{25}}{4} \\
& =\frac{0.83+0.66+0.89+0.83}{4}=0.74 .
\end{aligned}
$$

The mean value of the spearman ranking correlation coefficient between expert $k_{3}$ and all the other experts is

$$
\begin{aligned}
\overline{\rho_{3}} & =\frac{\rho_{31}+\rho_{32}+\rho_{34}+\rho_{35}}{4} \\
& =\frac{0.94+0.66+0.71+0.43}{4}=0.69 .
\end{aligned}
$$

\begin{tabular}{|c|c|c|c|c|}
\hline \multirow{2}{*}{ Criterion } & \multirow{2}{*}{$\begin{array}{l}\text { Potential } \\
\text { locations }\end{array}$} & \multicolumn{3}{|c|}{ Experts assessments } \\
\hline & & $k_{1}$ & $k_{2}$ & $k_{4}$ \\
\hline \multirow{3}{*}{$C_{1}$} & $L_{1}$ & $\mathrm{G}$ & VG & G \\
\hline & $L_{2}$ & $\mathrm{G}$ & G & VG \\
\hline & $L_{3}$ & G & G & G \\
\hline \multirow{3}{*}{$C_{2}$} & $L_{1}$ & $\mathrm{G}$ & VG & $\mathrm{VG}$ \\
\hline & $L_{2}$ & $\mathrm{~F}$ & $\mathrm{G}$ & G \\
\hline & $L_{3}$ & $\mathrm{P}$ & $\mathrm{F}$ & $\mathrm{P}$ \\
\hline \multirow{3}{*}{$C_{3}$} & $L_{1}$ & $\mathrm{~F}$ & $\mathrm{G}$ & $\mathrm{G}$ \\
\hline & $L_{2}$ & $\mathrm{~F}$ & $\mathrm{~F}$ & $\mathrm{~F}$ \\
\hline & $L_{3}$ & $\mathrm{~F}$ & $\mathrm{~F}$ & G \\
\hline \multirow{3}{*}{$C_{4}$} & $L_{1}$ & G & G & G \\
\hline & $L_{2}$ & $\mathrm{~F}$ & G & $\mathrm{F}$ \\
\hline & $L_{3}$ & $\mathrm{~F}$ & G & $\mathrm{G}$ \\
\hline \multirow{3}{*}{$C_{5}$} & $L_{1}$ & $\mathrm{G}$ & G & $\mathrm{G}$ \\
\hline & $L_{2}$ & $\mathrm{G}$ & G & $\mathrm{F}$ \\
\hline & $L_{3}$ & $\mathrm{~F}$ & G & $\mathrm{P}$ \\
\hline \multirow{3}{*}{$C_{6}$} & $L_{1}$ & $\mathrm{~F}$ & $\mathrm{~F}$ & $\mathrm{~F}$ \\
\hline & $L_{2}$ & $\mathrm{~F}$ & $\mathrm{P}$ & $\mathrm{P}$ \\
\hline & $L_{3}$ & $\mathrm{P}$ & VP & VP \\
\hline
\end{tabular}

TABLE 7: The performance rating of the potential locations.

The mean value of the spearman ranking correlation coefficient between expert $k_{4}$ and all the other experts is

$$
\begin{aligned}
\overline{\rho_{4}} & =\frac{\rho_{41}+\rho_{42}+\rho_{43}+\rho_{45}}{4} \\
& =\frac{0.89+0.89+0.71+0.71}{4}=0.8 .
\end{aligned}
$$

The mean value of the spearman ranking correlation coefficient between expert $k_{5}$ and all the other experts is

$$
\begin{aligned}
\overline{\rho_{5}} & =\frac{\rho_{51}+\rho_{52}+\rho_{53}+\rho_{54}}{4} \\
& =\frac{0.66+0.83+0.43+0.71}{4}=0.66 .
\end{aligned}
$$


TABLE 8: The aggregate fuzzy weights of each criterion.

\begin{tabular}{lcccc}
\hline Criterion & & \multicolumn{2}{c}{ Experts assessments } & Aggregate fuzzy weighs \\
\hline$C_{1}$ & $k_{1}$ & $k_{3}$ & $(7,9,9)$ \\
$C_{2}$ & $(7,9,9)$ & $(7,9,9)$ & $(7,9,9)$ & $(1,4.33,7)$ \\
$C_{3}$ & $(3,5,7)$ & $(1,3,5)$ & $(3,5,7)$ & $(5,8.33,9)$ \\
$C_{4}$ & $(5,7,9)$ & $(7,9,9)$ & $(7,9,9)$ & $(5,8.33,9)$ \\
$C_{5}$ & $(7,9,9)$ & $(5,7,9)$ & $(7,9,9)$ & $(3,6.33,9)$ \\
$C_{6}$ & $(5,7,9)$ & $(3,5,7)$ & $(5,7,9)$ & $(5,8.33,9)$ \\
\hline
\end{tabular}

TABLE 9: The aggregate fuzzy rating of potential locations with respect to each criterion.

\begin{tabular}{cccccc}
\hline \multirow{2}{*}{ Criterion } & Potential locations & $k_{1}$ & $k_{2}$ & $k_{3}$ & aggregate fuzzy ratings \\
\hline \multirow{2}{*}{$C_{1}$} & $L_{1}$ & $(5,7,9)$ & $(7,9,9)$ & $(5,7,9)$ & $(5,7.66,9)$ \\
& $L_{2}$ & $(5,7,9)$ & $(5,7,9)$ & $(7,9,9)$ & $(5,7.66,9)$ \\
\hline \multirow{2}{*}{$C_{2}$} & $L_{3}$ & $(5,7,9)$ & $(5,7,9)$ & $(5,7,9)$ & $(5,7,9)$ \\
& $L_{1}$ & $(5,7,9)$ & $(7,9,9)$ & $(7,9,9)$ & $(5,8.33,9)$ \\
& $L_{2}$ & $(3,5,7)$ & $(5,7,9)$ & $(5,7,9)$ & $(3,6.33,9)$ \\
$C_{3}$ & $L_{3}$ & $(1,3,5)$ & $(3,5,7)$ & $(1,3,5)$ & $(1,3.66,7)$ \\
& $L_{1}$ & $(3,5,7)$ & $(5,7,9)$ & $(5,7,9)$ & $(3,6.33,9)$ \\
& $L_{2}$ & $(3,5,7)$ & $(3,5,7)$ & $(3,5,7)$ & $(3,5.67)$ \\
$C_{4}$ & $L_{3}$ & $(3,5,7)$ & $(3,5,7)$ & $(5,7,9)$ & $(5,7,9)$ \\
& $L_{1}$ & $(5,7,9)$ & $(5,7,9)$ & $(5,7,9)$ & $(3,5.66,9)$ \\
\hline \multirow{2}{*}{$C_{5}$} & $L_{2}$ & $(3,5,7)$ & $(5,7,9)$ & $(3,5,7)$ & $(3,6.33,9)$ \\
& $L_{3}$ & $(3,5,7)$ & $(5,7,9)$ & $(5,7,9)$ & $(5,7,9)$ \\
& $L_{1}$ & $(5,7,9)$ & $(5,7,9)$ & $(5,7,9)$ & $(1,5,9)$ \\
$C_{6}$ & $L_{2}$ & $(5,7,9)$ & $(5,7,9)$ & $(3,5,7)$ & $(3,5,7)$ \\
& $L_{3}$ & $(3,5,7)$ & $(5,7,9)$ & $(1,3,5)$ & $(1,3.66,7)$ \\
\hline
\end{tabular}

Step 1.5 (compute the historical assessment accuracy of all the experts). The mutual history of the experts with respect to each criterion is shown in Table 4.

Calculate the historical assessment accuracy of the experts with respect to each criterion using (6); see Table 5.

Step 1.6. Compute the mean value of the historical assessment accuracy of the experts using (7):

$$
\begin{aligned}
\overline{A_{1}} & =\frac{A_{11}+A_{12}+A_{13}+A_{14}+A_{15}+A_{16}}{6} \\
& =\frac{0.5+0.8+0.6+1+0.8+0.5}{6}=0.7, \\
\overline{A_{2}} & =\frac{A_{21}+A_{22}+A_{23}+A_{24}+A_{25}+A_{26}}{6} \\
& =\frac{0.57+1+1+0.5+0.6+1}{6}=0.78,
\end{aligned}
$$

$$
\begin{aligned}
\overline{A_{3}} & =\frac{A_{31}+A_{32}+A_{33}+A_{34}+A_{35}+A_{36}}{6} \\
& =\frac{0.5+0.44+0.75+0.25+0.5+0.5}{6}=0.49, \\
\overline{A_{4}} & =\frac{A_{41}+A_{42}+A_{43}+A_{44}+A_{45}+A_{46}}{6} \\
& =\frac{1+0.4+1+0.67+1+1}{6}=0.85, \\
\overline{A_{5}} & =\frac{A_{51}+A_{52}+A_{53}+A_{54}+A_{55}+A_{56}}{6} \\
& =\frac{0.5+0.4+0.67+1+0.67+0.53}{6}=0.63 .
\end{aligned}
$$

Step 1.7 (compute the credibility of the experts using (2)). In this paper, consider that the consistency level is as important as the accuracy level; set the weight $\alpha=0.5$ :

$$
C_{1}=0.5 \overline{\rho_{1}}+0.5 \overline{A_{1}}=0.77 \text {, }
$$




$$
\begin{aligned}
& C_{2}=0.5 \overline{\rho_{2}}+0.5 \overline{A_{2}}=0.76, \\
& C_{3}=0.5 \overline{\rho_{3}}+0.5 \overline{A_{3}}=0.69, \\
& C_{4}=0.5 \overline{\rho_{4}}+0.5 \overline{A_{4}}=0.83, \\
& C_{5}=0.5 \overline{\rho_{5}}+0.5 \overline{A_{5}}=0.65 .
\end{aligned}
$$

In this paper, we set the credibility threshold value of the experts $T=0.7$. According to the result above, experts $k_{1}, k_{2}$, and $k_{4}$ pass the credibility check and perform the following assessments. The performance rating of the 6 criteria and the potential locations are shown in Tables 6 and 7.

Step 2. Compute the aggregate fuzzy weights of each criterion using (8); see Table 8.

Step 3. Evaluate the aggregate fuzzy rating of potential locations with respect to each criterion using (9); see Table 9.

Step 4. Normalize the aggregate fuzzy ratings using (10); see Table 10.

Step 5. Compute final evaluation for potential locations using (11); see Table 11.

The final fuzzy evaluation values are

$$
\begin{gathered}
p_{1}=(13.76,28.19,52), \\
p_{2}=(11,26.68,54), \\
p_{3}=(12.69,27.33,52) .
\end{gathered}
$$

Step 6. Compare the potential locations using (12) and (13); results are as follows.

The fuzzy preference matrix is

$$
E=\left(\begin{array}{ccc}
0.50 & 0.75 & 1 \\
0.25 & 0.50 & 0.41 \\
0 & 0.59 & 0.50
\end{array}\right)
$$

According to the computing result, compare the three potential locations using (14), $p_{1}>p_{3}$ and $p_{3}>p_{2}$; therefore, $p_{1}$ is the best location to establish the logistics center.

\section{Conclusions}

The multiple-criteria decision making approach based on fuzzy theory and credibility mechanism proposed in this paper has taken both quantitative criteria and qualitative criteria under uncertain environment into consideration. Moreover, the credibility mechanism which is composed by the consistency level and the historical assessment accuracy solved the inaccuracy caused by the different credibility of experts and improved the reliability of the logistic center location selection. The method proposed in this paper is a better one in logistic center location than traditional algorithms.
TABLE 10: The final fuzzy evaluation value for potential locations.

\begin{tabular}{lccc}
\hline Criterion & \multicolumn{3}{c}{ Normalized ratings } \\
& $L_{1}$ & $L_{2}$ & $L_{3}$ \\
\hline$C_{1}$ & $(0.56,0.65,1)$ & $(0.56,0.65,1)$ & $(0.56,0.71,1)$ \\
$C_{2}$ & $(0.56,0.60,1)$ & $(0.33,0.47,1)$ & $(0.14,0.27,1)$ \\
$C_{3}$ & $(0.33,0.47,1)$ & $(0.43,0.60,1)$ & $(0.33,0.53,1)$ \\
$C_{4}$ & $(0.56,0.78,1)$ & $(0.33,0.63,1)$ & $(0.33,0.70,1)$ \\
$C_{5}$ & $(0.56,0.78,1)$ & $(0.33,0.70,1)$ & $(0.11,0.56,1)$ \\
$C_{6}$ & $(0.43,0.60,1)$ & $(0.14,0.27,1)$ & $(0.20,0.60,1)$ \\
$p_{i}$ & $(0.56,0.65,1)$ & $(0.56,0.65,1)$ & $(0.56,0.71,1)$ \\
\hline
\end{tabular}

TABLE 11: The final fuzzy evaluation value for potential locations.

\begin{tabular}{lccc}
\hline Criterion & \multicolumn{3}{c}{ Experts assessments } \\
& $L_{1}$ & $L_{2}$ & $L_{3}$ \\
\hline$C_{1}$ & $(3.92,5.85,9)$ & $(3.92,5.85,9)$ & $(3.92,6.39,9)$ \\
$C_{2}$ & $(0.56,3.00,7)$ & $(1.65,3.9,9)$ & $(2.14,3.17,7)$ \\
$C_{3}$ & $(1.65,3.9,9)$ & $(2.15,5,9)$ & $(1.65,4.4,9)$ \\
$C_{4}$ & $(2.8,5.50,9)$ & $(1.65,5.25,9)$ & $(1.65,5.83,9)$ \\
$C_{5}$ & $(2.68,4.94,9)$ & $(1,4.43,9)$ & $(2.33,3.54,9)$ \\
$C_{6}$ & $(2.15,5,9)$ & $(0.7,2.25,9)$ & $(1,5,9)$ \\
$p_{i}$ & $(13.76,28.19,52)$ & $(11,26.68,54)$ & $(12.69,27.33,52)$ \\
\hline
\end{tabular}

\section{Conflict of Interests}

The authors declare that there is no conflict of interests regarding the publication of this paper.

\section{Acknowledgments}

This research was supported by the Collaborative Innovation Centre for State-owned Assets Administration of Beijing Technology and Business University (approval no. GZ20131102), Scientific Research Common Program of Beijing Municipal Commission of Education under Grant KM201310011009, and the National Natural Science Foundation of China under Grant 71201004.

\section{References}

[1] G. Tuzkaya, S. Önüt, U. R. Tuzkaya, and B. Gülsün, "An analytic network process approach for locating undesirable facilities: an example from Istanbul, Turkey," Journal of Environmental Management, vol. 88, no. 4, pp. 970-983, 2008.

[2] M. A. Badri, "Combining the analytic hierarchy process and goal programming for global facility location-allocation problem," International Journal of Production Economics, vol. 62, no. 3, pp. 237-248, 1999.

[3] H. Zhang, Y. Deng, F. T. S. Chan, and X. Zhang, "A modified multi-criterion optimization genetic algorithm for order distribution in collaborative supply chain," Applied Mathematical Modelling, vol. 37, no. 14-15, pp. 7855-7864, 2013.

[4] F. T. S. Chan and S. H. Chung, "Multi-criteria genetic optimization for distribution network problems," International Journal of Advanced Manufacturing Technology, vol. 24, no. 7-8, pp. 517$532,2004$. 
[5] G. S. Liang and M. J. J. Wang, "Fuzzy multi-criteria decisionmaking method for facility site selection," International Journal of Production Research, vol. 29, no. 11, pp. 2313-2330, 1991.

[6] F. T. S. Chan, N. Kumar, M. K. Tiwari, H. C. W. Lau, and K. L. Choy, "Global supplier selection: a fuzzy-AHP approach," International Journal of Production Research, vol. 46, no. 14, pp. 3825-3857, 2008.

[7] T. C. Chu, "Facility location selection using fuzzy TOPSIS under group decisions," International Journal of Uncertainty, Fuzziness and Knowledge-Based Systems, vol. 10, no. 6, pp. 687-701, 2002.

[8] E. Gundogar and B. Erkayman, "A fuzzy TOPSIS approach for logistics center location selection," Journal of Business Case Studies, vol. 7, no. 3, pp. 49-55, 2012.

[9] S. Liu, F. T. S. Chan, and S. H. Chung, "A study of distribution center location based on the rough sets and interactive multi-objective fuzzy decision theory," Robotics and ComputerIntegrated Manufacturing, vol. 27, no. 2, pp. 426-433, 2011.

[10] C. Kahraman, D. Ruan, and I. Doǧan, "Fuzzy group decisionmaking for facility location selection," Information Sciences, vol. 157, no. 1-4, pp. 135-153, 2003.

[11] F. Chan and A. Prakash, "Maintenance policy selection in manufacturing firms using the fuzzy MCDM approach," International Journal of Production Research, vol. 50, no. 23, pp. 7044-7056, 2012.

[12] K. L. Lee and S. C. Lin, "A fuzzy quantified SWOT procedure for environmental evaluation of an international distribution center," Information Sciences, vol. 178, no. 2, pp. 531-549, 2008.

[13] L. A. Zadeh, "Fuzzy sets," Information and Computation, vol. 8, no. 2, pp. 338-353, 1965.

[14] X. Jie, Z. Kai, T. Yuan, and R. Yihong, "Research of logistic center location and case analysis," Journal of Northern JiaoTong University, vol. 25, no. 5, pp. 80-82, 2001.

[15] L. Renhou, Intelligent Control Theory and Method, Xian Electronic and Science University Press, Xi'an, China, 1999.

[16] Y. Shan, "An positive analysis of the rank correlation coefficient," Studies of Finance and Economics, vol. 3, 68 pages, 1999.

[17] Y. Liu, "A kind of combination evaluation method that revise circularly," Mathematics in Practice and Theory, vol. 37, pp. 8894, 2007. 


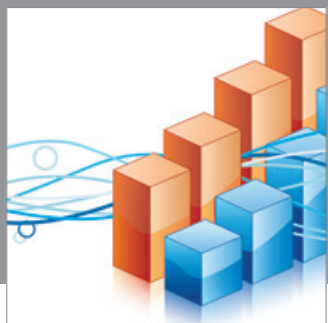

Advances in

Operations Research

mansans

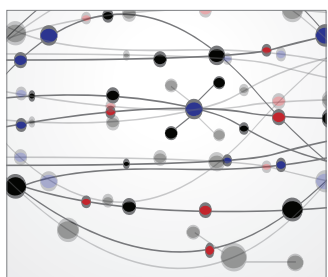

The Scientific World Journal
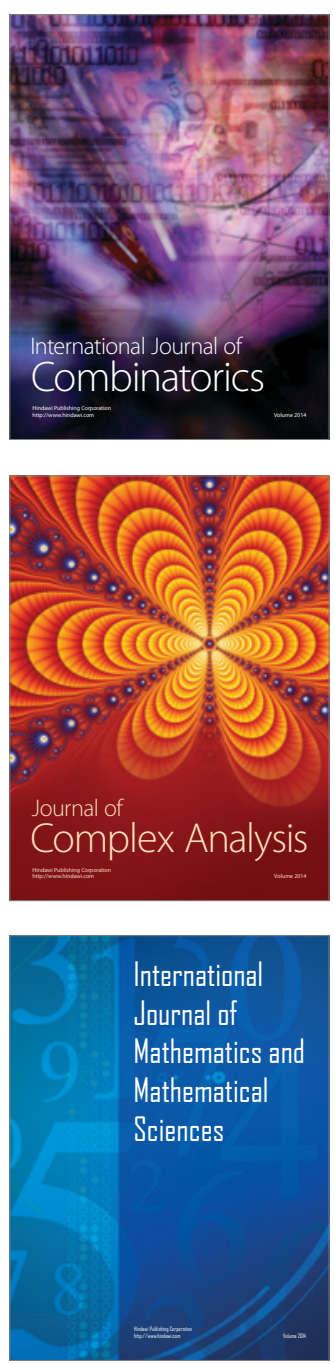
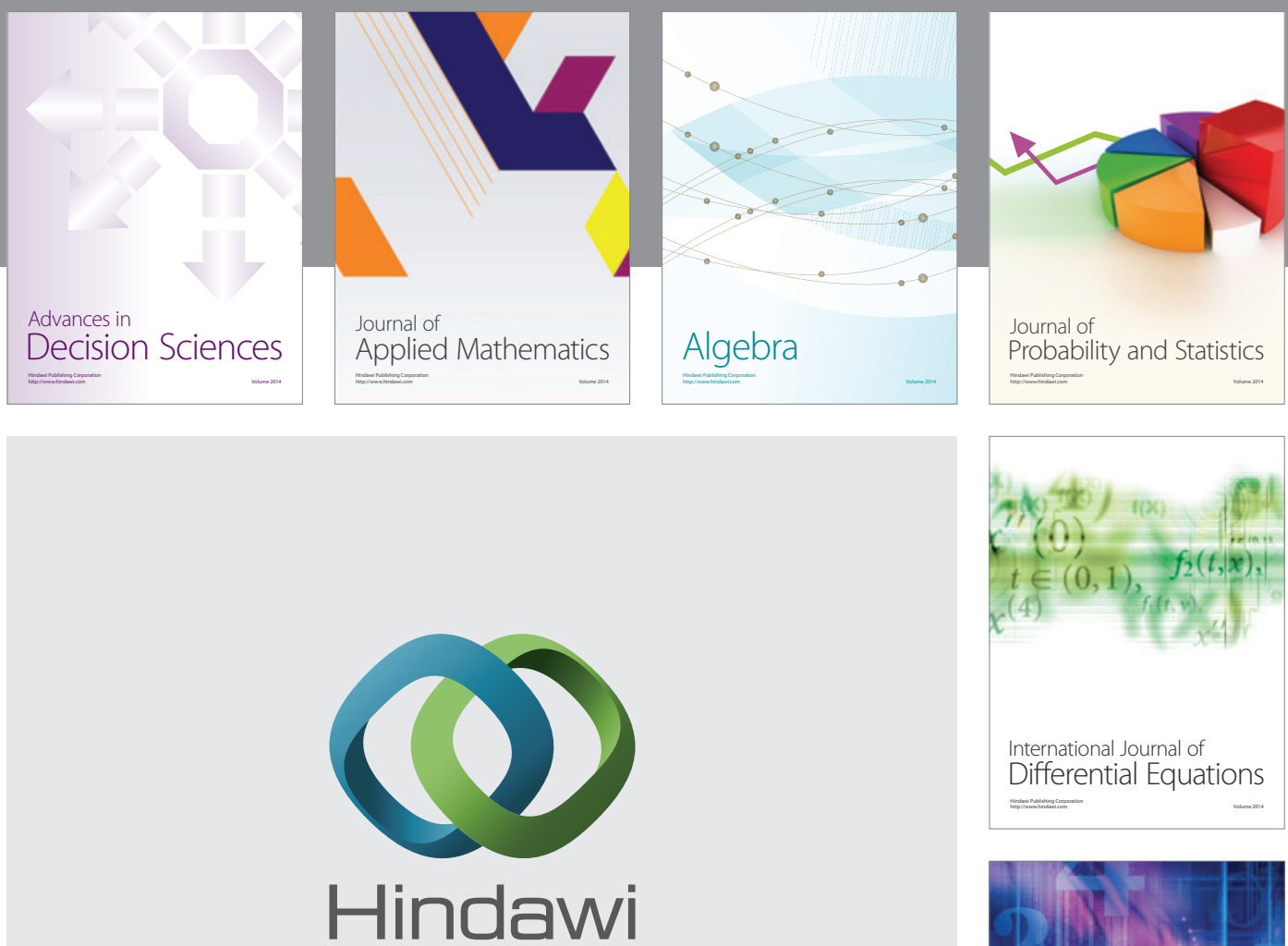

Submit your manuscripts at http://www.hindawi.com
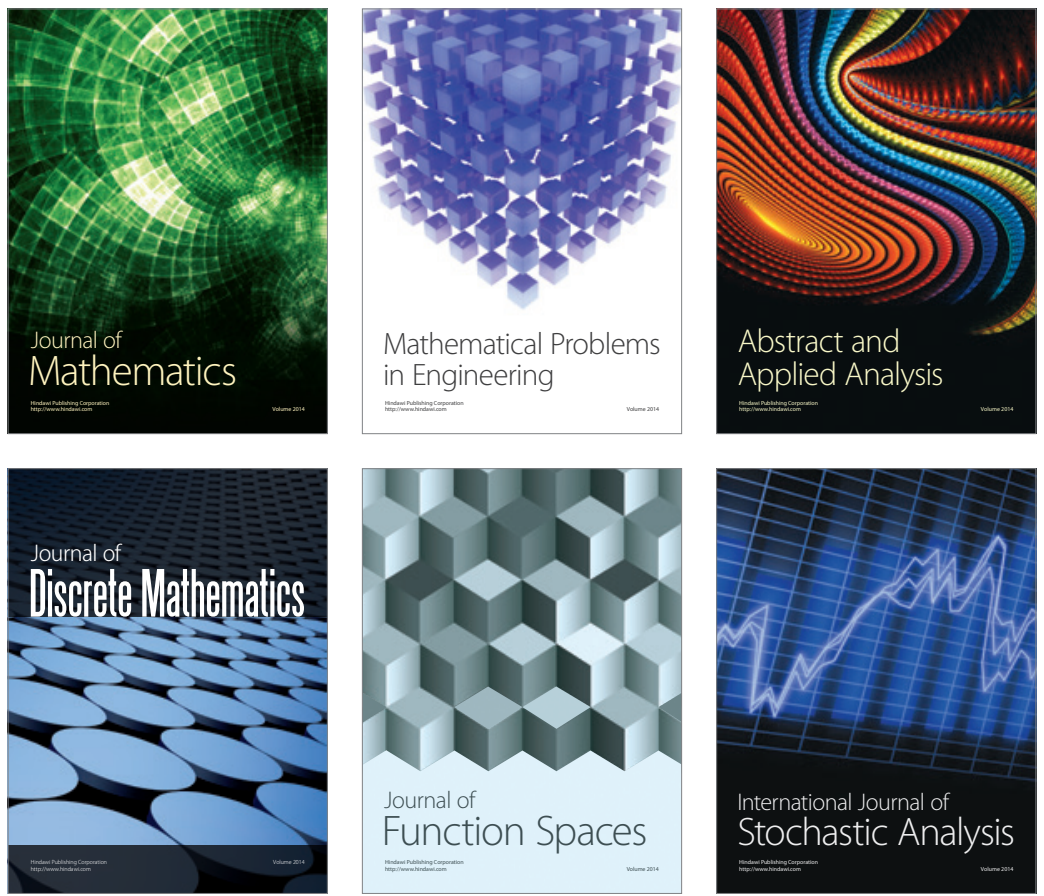

Journal of

Function Spaces

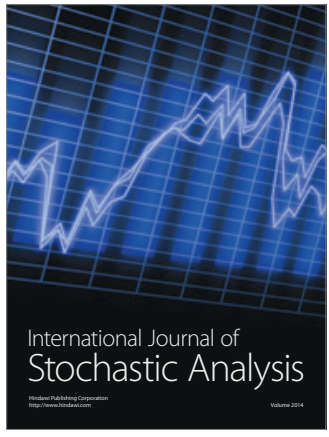

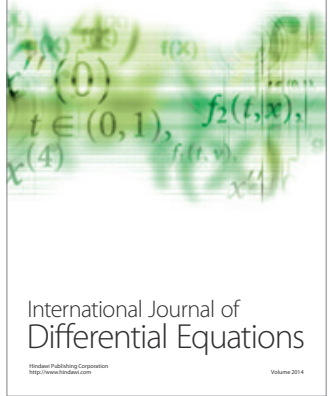
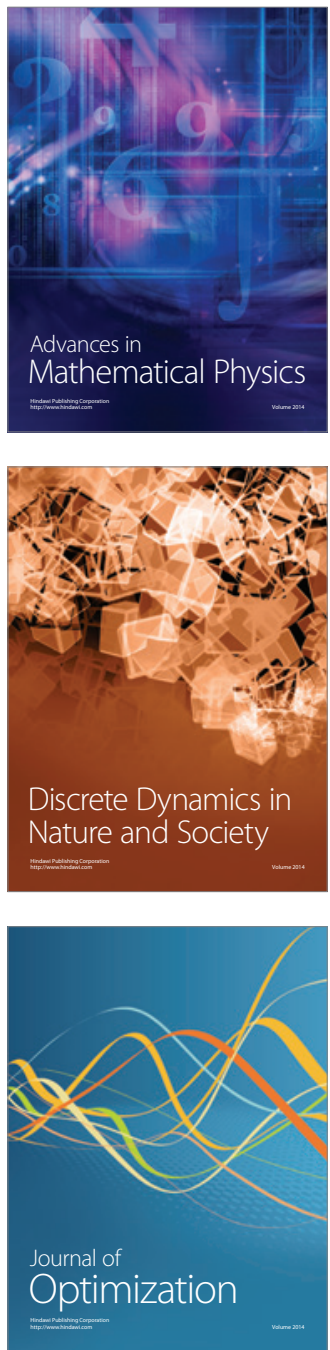